IJSMS

22,2

\section{2}

Received 11 December 2019 Revised 28 March 2020 Accepted 14 May 2020

\title{
Insights into customer experience in sports retail stores
}

\author{
Elisabeth Happ \\ Department of Sport Science, University of Innsbruck, Innsbruck, Austria \\ Ursula Scholl-Grissemann \\ Private University Schloss Seeburg, Seekirchen am Wallersee, Salzburg, Austria \\ Mike Peters \\ Department of Strategic Management, Marketing and Tourism, \\ University of Innsbruck, Innsbruck, Austria, and \\ Martin Schnitzer \\ Department of Sport Science, University of Innsbruck, Innsbruck, Austria
}

\begin{abstract}
Purpose - Offline retail stores have been working on improving their in-store customer experience; they have begun to realise the physical advantage they have over online channels. Especially sports products have a number of unique features, such as high emotional involvement or a sense of community; additionally, sports customers put emphasis on multisensory brand experience at the point of sale. This study examines the in-store customer experience (ISCX) in offline sports retail stores, taking into account the commercial uniqueness of sport.
\end{abstract}

Design/methodology/approach - A qualitative study (focus groups; $n=16$ ) and quantitative survey (cross-sectional survey design; $n=238$ ) were conducted to measure ISCX in sports retail stores.

Findings - The results suggest that the customers' in-store experience has a significant influence on customers' satisfaction with the sports retailer and their likeliness to recommend the store to friends, which, in turn, is significantly affected by customers' satisfaction with the retailer. Moreover, social responses to actors involved in the service encounter, for example, the interaction with employees, play a significant role for the customer in-store experience. Accordingly, sports customers strive not only for functional benefits inherent in the interaction with customers and employees but also for social benefits.

Originality/value - This study extends the knowledge by (1) replicating the ISCX scale, (2) analysing ISCX in a sports retail environment and (3) examining the influence of ISCX on the Net Promoter Score. Moreover, the findings support managers' know-how about in-store setting and help to maintain the customer relationship.

Keywords Satisfaction, In-store customer experience, ISCX, Rate of recommendation, Sports retail Paper type Research paper

\section{Introduction}

Mullin et al. (2007) argued that sport products have several unique features: first, a high level of emotional involvement; second, a sense of community; and third, constantly changing and unpredictable preferences. Furthermore, trends have an influence on sports retail customers and their behaviour. They have become a considerable line of business. An excellent examples is the athleisure trend (sales volume of the US athleisure market in 2015: 44 billion dollar) (Eurostat, 2019): clothing designed for workouts and other athletic activities is worn in different settings, such as at the workplace, at school or at other casual or social occasions (Bielefeldt Bruun and Langkjær, 2016). Trends like this and the uniqueness of sports products

(C) Elisabeth Happ, Ursula Scholl-Grissemann, Mike Peters and Martin Schnitzer. Published by Emerald Publishing Limited. This article is published under the Creative Commons Attribution (CC BY 4.0) licence. Anyone may reproduce, distribute, translate and create derivative works of this article (for both commercial \& non-commercial purposes), subject to full attribution to the original publication and authors. The full terms of this licence may be seen at http://creativecommons.org/licences/by/4.0/ legalcode.

International Journal of Sports Marketing and Sponsorship Vol. 22 No. 2, 2021 pp. $312-329$ Emerald Publishing Limited 1464-6668

DOI 10.1108/IJSMS-12-2019-0137
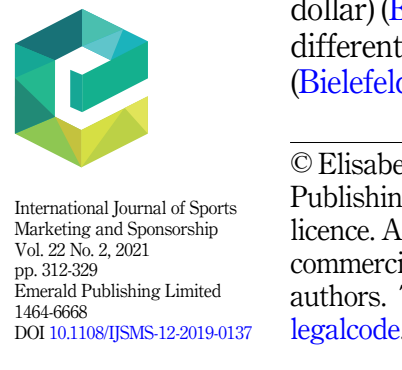
and sports customers require appropriate sports retail settings to increase customer satisfaction and loyalty. In other words, the context of sport and retailing is faced with several peculiarities distinguishing it from other lines of business; these peculiarities have to be taken into consideration when creating a positive customer experience $(\mathrm{CX})$ in a sports retail store.

Furthermore, the online-offline battle cannot be concealed. Over the last decade, online retailers' promotional efforts, such as price discounts and free shipping, have significantly increased their competitiveness relative to traditional offline retailers (Grewal et al., 2009). Many sports brands use online and offline channels as complementary strategies, and an increasing fraction of customers shop both online and offline (Wang and Goldfarb, 2017). Nevertheless, there is no denying that online business - in contrast to offline business - has been increasing every year, also in the sports industry. E-shoppers in Europe mostly purchase clothes and sports goods (64\% of the purchases); within the 16-24 age group, clothes and sports goods even accounted for $72 \%$ of all purchases (Eurostat, 2019).

Marketing practitioners claim that online and offline channels complement each other, which means that rivalry between offline stores and online channels is a fact on the market place (Beck, 2013). Retailers with offline stores have begun to realise that they have a physical advantage over pure online players, and that it is important to utilise this chance. In particular, an offline channel may complement an online channel in terms of service quality - that is, by highlighting the possibility of a rich, multisensory brand experience and the salespeople's ability to improve the service experience (Herhausen et al., 2015). For customers in Europe, the main reasons for not shopping online are the chance to see the product before purchasing it $(69 \%)$ and to get support from salespeople in case of lacking skills and knowledge $(19 \%)$ (Eurostat, 2019). All these aspects highlight the importance of satisfying ISCX.

Customer experience is widely recognised as the internal and subjective response customers have to any interaction with a company (Meyer and Schwager, 2007; Verhoef et al., 2009). Jerry Gregoire, former CIO of Dell, maintained that "the customer experience is the next competitive battleground" (De Keyser et al., 2015). CX is thus a cornerstone of marketing and may be one of the advantages of and chances for offline retail stores (De Keyser et al., 2015).

Since Hirschman and Holbrook (1982) first recognised the experiential dimension of customer behaviour, numerous studies have stressed the need for in-depth study of the role of CX in marketing, particularly in retailing (Lemon and Verhoef, 2016; Lipkin, 2016; Marketing Science Institute, 2016), and argued the need for more scholarly research in different contexts to develop comprehensive knowledge about CX, its formation, effectiveness and implementation (Lemon and Verhoef, 2016). Bustamente and Rubio (2017) conceptualised and validated a comprehensive scale to measure ISCX, taking into account the specifics of customer experience in stores.

Previous studies in the sports sector have investigated experience and customer experience by using different lenses. Authors measuring customer experience have focused predominantly on the value-experience relation and its influence on satisfaction and loyalty (e.g. Calabuig et al., 2015; García-Fernández et al., 2018; Nuviala et al., 2012), whereas authors measuring customer experience in sport have primarily put their emphasis on sports events and sports participation (Clemes et al., 2011; Funk, 2017; Greenwell et al., 2002; Horbel et al., 2016; Hwang and Lee, 2018). Therefore, there is still a lack in research measuring customer experience - and especially in-store customer experience (ISCX) - in sports settings and analysing the retail-customer perspective instead of the much-studied event spectator or event participant perspective.

The objective of the present study was to take into account the ongoing battle for customers in the online and offline sports retail market. In the context of this paper, a sports retail store is a store that trades exclusively with sporting goods, including sports hardware (e.g. skis) and sports software (e.g. apparel). Correspondingly, we use the terms "sports shoppers" and "sports customers" for clients of these stores. 
IJSMS

22,2

314

The first goal was to provide deeper insights into the construct of ISCX in sports retail stores. The second aim was a) to implement CX - and in particular ISCX - in the field of sports management (i.e. in sports retailing) by replicating the ISCX scale developed by Bustamente and Rubio (2017) in a sport context, and b) to examine the influence of ISCX on the Net Promoter Score (NPS). Funk (2017) highlighted the lack of studies replicated from other disciplines and extended to fit a sport context. Replication is important in the progress of research. As an indispensable ingredient of the academic discourse, replication studies serve an important function (Block and Kuckertz, 2018; Kuppelwieser and Klaus, 2020). Management research is often obsessed with novelty or originality; at the same time, the academic community is increasingly concerned that novel findings might be nonreplicable artefacts. Consequently, there is a plethora of replication studies, which the discipline requires to develop in a meaningful way and close the theory-practice gap (Block and Kuckertz, 2018).

ISCX is a multidimensional construct produced by aggregating specific components that measure customers' internal (cognitive, affective and physical) and social responses including also the aspects of customer satisfaction and loyalty. This study emphasises the importance of discussing the commercial and cultural uniqueness of sport and sports retail customers in the sports marketing and management field (Gammelsæter, 2020; Smith and Stewart, 2010, 2015) and follows the call for research in CX in different contexts (Lemon and Verhoef, 2016).

\section{Literature review}

\subsection{Peculiarities of the sports industry}

Sport has an ambiguous history when viewed from a management perspective. As Stewart and Smith (1999) as well as Smith and Stewart (2010) noted, there are traditionally two contrasting philosophical approaches to the management of sport: One stream sees sport as a unique cultural institution with a host of special features, wherein the reflexive application of standard business practices not only produce poor management decision-making but also erode the rich history, emotional connections and social relevance of sport. The other stream views sport as nothing more than just another generic business enterprise that is subject to the usual government regulations, market pressure and customers' demands and is therefore best managed by the application of standard business tools that assist the planning, finance, human resource management and marketing functions. Over time, these divisions have been blurred due to the corporatisation of sport and through the emergence of sports management as an academic discipline. In fact, there are distinct and special features, which make sport a unique business institution (Gammelsæter, 2020; Hess et al., 2008; Smith and Stewart, 2010). Likewise, as Szymanski (2009) underlined in his research, sports management and sports marketing are unique and differ from other business branches.

Given the peculiarities sport offers, it is natural that (1) sports products, (2) customers of sporting goods and (3) sports customer experience show distinct features, too. Sports scholars and educators highlight the intrinsic characteristics of sports products and link them to the uncertainty of outcomes, fluctuations in supply and demand, the intangibility and inconsistent nature of sport, reliance on product extensions, sports customers' increasing knowledge and the manner in which sport is consumed in the presence of others (Shilbury et al., 2014).

In contrast to a classic hedonic shopper, for whom the shopping process is driven by fun, spontaneity and impulsivity, a sport shopper as understood by Chiu and Leng (2015) and O'Donnell et al. (2016) has task-oriented, ego-oriented and social approval-oriented goals and thus can be assigned the attributes highly focused, task-driven and rational (Chiu and Leng, 2015; Gammelsæter, 2020); in that case, shopping itself is not necessarily/exclusively a 
recreational or leisure activity but a kind of sport (O'Donnell et al., 2016). We take these attributes into account; however, in this paper, we use the terms "sports shoppers" and "sports customers" synonymously, namely, for clients of sports retail stores, who purchase all kinds of sports-related goods, including sports hardware (e.g. equipment) and sports software (e.g. apparel). Their in-store experience is in the focus of this contribution.

Referring to sports customer experience, a growing number of sports management and sports marketing researchers have recognised the importance of service quality. Enhancing the holistic customer experience is one of the most important issues among both goods manufacturers and retail stores (Yoshida et al., 2013). Furthermore, Kwak et al. (2011) confirmed that sport provides a unique opportunity to explore how emotions operate in people (Knobloch-Westerwick et al., 2009). Undoubtedly, strong emotional responses (e.g. suspense, arousal, excitement) are central to the sport consumption experience, for spectators (e.g. Knobloch-Westerwick et al., 2009; Madrigal and Chen, 2008) as well as for participants (e.g. Zuckerman, 2007). Funk (2017) introduced the Sport Experience Design (SX) framework, which consists of three interrelated elements: (1) the sport context, in which a sports customer navigates through an experience and interacts with touch points, (2) the sports user with mental processes, psychological needs and personal characteristics and (3) the sports organisation, which produces the sport experience to achieve organisational goals. Scattered research on the sports industry in particular has been done (e.g. Liu, 2016; Lohman et al., 2004). Nevertheless, two main gaps remain. First, the aforementioned studies focused on sports events and/or sports participants and disregarded sports retail customers and their experience; and second, there is a lack of studies replicated from other disciplines and extended to fit a sport context (Funk, 2017). Finally, the assumption that sport has unique characteristics (Funk, 2006) could result in the fact that ISCX in sports retail stores differs from ISCX and CX in other retail branches.

\subsection{In-store customer experience (ISCX)}

Following the customer experience perspective provided by Meyer and Schwager (2007), Verhoef et al. (2009) as well as Lemon and Verhoef (2016), sports customer experience is defined as sports customers' cognitive, affective, social and physical reactions to direct (e.g. purchase and consumption) and indirect (e.g. media and social network) encounters with a sports organisation, its products and other customers (Yoshida et al., 2013). Taking this definition in consideration, we decided to take the ISCX scale (Bustamente and Rubio, 2017) as fundament for our study. ISCX is a multidimensional construct formed by individual cognitions, feelings as well as social and physical responses to a service that occur as a result of encountering, undergoing or living through the customer shopping visit to the offline store (Lemon and Verhoef, 2016; Lipkin, 2016; Verhoef et al., 2009).

Bustamente and Rubio (2017) conceptualised and validated a comprehensive scale to measure ISCX. They defined CX in the service context as having both internal and contextual components. As CX is "lived" by the customer, it includes the customer's internal (cognitive, affective and physical) processes experienced during the visit to the offline store. However, $\mathrm{CX}$ is only partly internal since service contexts have a social dimension determined by the interaction between customers and other actors involved in the service encounter (Heinonen et al., 2013; Helkkula et al., 2012).

The ISCX scale of Bustamente and Rubio (2017) is more comprehensive than that developed by Bagdare and Jain (2013), which conceptually limits the lived ISCX to the affective component. Bustamente and Rubio (2017) analysed ISCX in the retail setting as a holistic construct that includes the customer's internal (cognitive, affective and physical) responses to the service stimuli and the customer's social interaction with other actors involved in the service encounter. Consequently, their ISCX approach confirms the existence

\section{Customer experience in sports retail stores}


IJSMS

22,2

of the four components - cognitive, affective, social and physical - that were identified by Verhoef et al. (2009) in their conceptual framework of CX in the retail service context. ISCX is thus conceived as a multidimensional construct produced by aggregating specific components that measure customers' internal and social responses.

\subsection{Satisfaction with sports retailers}

There is a well-documented management shift from goods- to service-centred approaches (Brodie, 2006). In the areas of brands and services, respectively, Brakus et al. (2009) and Klaus and Maklan (2013) found that CX has a direct and positive relationship with customer satisfaction and loyalty.

In addition to the aforementioned shift from goods- to service-dominant marketing, creating extraordinary shopping experiences in stores is getting more and more interest. In a world where customer empowerment is continuously increasing and changing the service landscape, retailers must provide memorable shopping experiences to retain customers and attract new ones online and/or offline (Wang and Goldfarb, 2017). When customers decide to go shopping in an offline store, they expect to enjoy their visit by experiencing cognitive, affective, social and physical responses evoked by in-store stimuli; hence, the outcome satisfaction is incredibly important (Bustamente and Rubio, 2017). Various authors have argued that the right CX can increase customers' satisfaction and loyalty (Brakus et al, 2009; Klaus and Maklan, 2013; Meyer and Schwager, 2007; Verhoef et al., 2009). In a sport context, numerous studies have shown that customer satisfaction is a multidimensional construct that consists of two dimensions: core product satisfaction and service satisfaction (Wakefield and Blodgett, 1996; Yoshida and James, 2010).

Adapting previous findings to the sports retail and sports marketing context, we hypothesised:

H1. In sports retail stores, a positive ISCX is positively related to customers' satisfaction with the store.

\subsection{NPS of sports retailers}

Reichheld (2003) claimed that the NPS is the sole metric required to understand the effectiveness of the business from a customer's perspective. Research has shown that, in most industries, there is a strong correlation between a company's growth rate and the percentage of its customers who are "promoters" - that is those who say they are extremely likely to recommend the company to a friend or colleague. Reicheld (2003) called this "the growth by word of mouth". The "would recommend" question of the NPS has generally been proved to be most effective in determining loyalty, predicting growth and word of mouth (Reichheld, 2003); however, one should not overstate the findings.

For many sports customers, sport is an important part of their lives, both for recreation and entertainment (Bielefeldt Bruun and Langkjær, 2016); therefore, a great and authentic customer experience in a sports retail store could lead to a higher recommendation rate. Accordingly, we hypothesise:

H2. In sports retail stores, a positive ISCX is positively related to customers' likeliness to recommend the store to a friend or colleague (Net Promoter Score).

The theoretical knowledge about ISCX, which forms the basis of this study, as well as the hypotheses derived from former findings, is summarised in Figure 1.

\section{Empirical studies}

We conducted two studies to address our research hypotheses. First, a qualitative focus group approach was applied in order to get more insights into the topic of in-store customer 


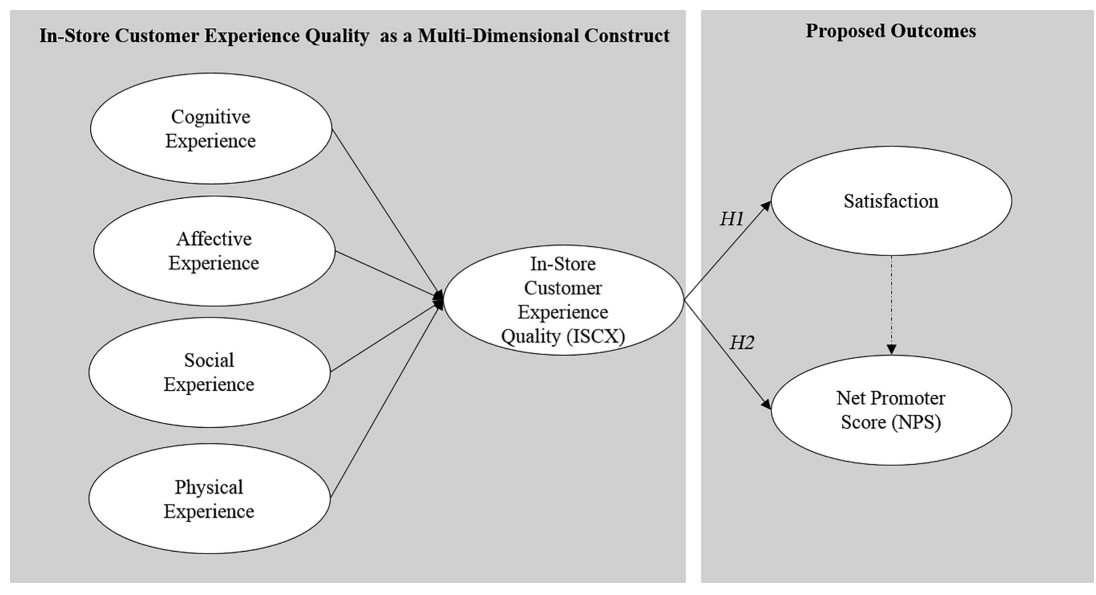

\section{Customer experience in sports retail stores}

Figure 1. Conceptual model

experience in sports retail stores (Study I). The findings from Study 1 justified that Study 2 focused on ISCX from a sports perspective.

Second, Study II extended the knowledge by (1) replicating the ISCX scale, (2) analysing ISCX in a sports retail environment and (3) examining the influence of ISCX on the NPS.

\subsection{Study I: Focus group approach}

3.1.1 Sample and study context. Due to the exploratory nature of Study I, a qualitative focus group approach was adopted (Kloosterman and Giebel, 2007) to answer two basic questions: Is there a difference between ISCX in sports stores and in non-sports stores and, if yes, what are the special features of ISCX in sports stores (Gammelsæter, 2020; Hess et al., 2008; Smith and Stewart, 2010)? Eventually, if there was no difference, there would be no need to qualitatively and quantitatively examine ISCX in a sport context. The assumption that there are distinct and special features that make sport a unique business institution (Gammelsæter, 2020; Hess et al., 2008; Smith and Stewart, 2010) served as basis.

Study I used two relatively large focus groups of eight participants each (Group A: eight experts, discussion time $55 \mathrm{~min}$; Group B: eight experts, discussion time $65 \mathrm{~min}$ ), because large groups ease participants' pressure to contribute and facilitate moderators' efforts to stimulate the discussions (David and Sutton, 2004). As focus group discussions work best with homogeneous groups (Litosseliti, 2003), the sample consisted of consumers who shared two major characteristics: they were experts in sports and event marketing, and customers of sports stores in Austria.

3.1.2 Measures. Each focus group was moderated by one sports marketing expert. The discussions were semi-structured, following a predesigned guideline to maintain focus. A brief ice-breaking session was held at the beginning of the discussions, allowing participants to become familiar with one another and setting the tone for the discussions. The topics covered were divided into five sections: (1) the importance of sport in people's lives personally and for the public, (2) sport and trends, (3) the role emotions play in sport, (4) the importance of service in sports retail and (5) shopping experience in sports stores versus non-sports stores.

3.1.3 Results of the focus group discussions. Based on the five themes named above, the results were grouped into four sections:

(1) All participants confirmed that sport has a high priority in their lives, but also in the public sphere, and is associated with many emotions. The participants saw 
IJSMS

22,2

\section{8}

themselves as experts in the field, as one participant (Group A) demonstrated: "[. . . ] Sport is a very important part of my life, I do a lot of sports and therefore I see myself somehow as an expert". For the participants the experience of shopping sports goods could not be compared to the experience of shopping non-sports goods. The special aspects of buying a sporting good - compared to purchasing other products - are that (1) people often want to "buy" a certain image (showing coolness, sportiness or belonging to a certain group with emotional value or significance) to support key aspects of their social identity (Tajfel, 1982), (2) people often expect a significant increase in their own performance due to the purchase and (3) emotions play a major role.

(2) The participants discussed extensively about trends. They often learned about trends from social media or trade fairs, but then waited until these trends (in terms of the respective items) were available in a store. Looking at the product, testing it and getting advice from sales staff were very important to them. In line with prior research on consumers' preference for haptic information (i.e. need for touch) and psychological ownership (e.g. Peck and Childers, 2003), it was found that the participants preferred to see/touch/try an item in a store, even if they were already well-informed about it (e.g. via online sources). Participants with a high level of expertise in a sport placed even more emphasis on testing products in the store or during sports, as one participant (Group A) explained: "[ . . . Especially when it comes to sports goods, testing is important to me. I want to know what the product feels like, how the freedom of movement is and whether the function meets my requirements". This is in accordance with Hertwig et al. (2004), who discussed an experience-based paradigm (like testing), where personal experience is taken into account for decisionmaking, as opposed to a description-based approach.

(3) The question of what makes sport so special resulted mainly in a discussion about emotions. The key point was that sport has its own specific characteristics, which often cannot be cognitively determined but are driven by emotions; this is consistent with the literature (e.g. Knobloch-Westerwick et al., 2009; Madrigal and Chen, 2008). The point became evident in the following statement (participant Group B): “. . .Sport is very strongly connected with emotions; I would even say that emotions make sport so special-it is not at all comparable to other areas of my life".

(4) The participants agreed that service in sports stores and the associated shopping experience are of great importance to them and are more important when buying sporting goods than when buying non-sporting goods. The participants stated to seek service for various reasons: (1) to have their own opinion (influenced by trends, knowledge gained online and via friends) confirmed and/or expanded by an expert, (2) to make sure that the product fits $100 \%$ and they can rely on it in every situation, especially in outdoor settings (trust in the retailer plays a key role here) and (3) to get advice from an experienced salesperson. One participant (Group B) stated: "[ . . . the opinion and above all the expertise of the salesperson is important to me. I want professional advice that gives me the feeling of confidence that, for example, I can use those ski mountaineering skis perfectly in extreme situations like harsh weather conditions with unexpected difficulties in terrain".

Overall, the results of the focus groups showed that there might be a difference between the shopping experience in a sports shop and a non-sports shop, building the base for the quantitative Study II. All participants agreed that buying sports goods has special characteristics, with the aforementioned four topics being the main aspects. 


\subsection{Study II survey}

3.2.1 Sample and study context. Know-how from literature research and the focus group discussions (Study I) entitled Study II to look at ISCX from a sports perspective; additionally, the feedback of the survey pretest was included. The studies are parts of a large research project on sports retail stores.

The present study utilised the ISCX of customers in sports retail stores in Tyrol, Austria, via a quantitative online questionnaire. Customers were contacted online via social media and asked to respond to a shopping experience in their favourite offline sports store. To be selected for the target sample, the participants had to answer two questions in the affirmative: (1) Do you have a favourite offline sports store? (2) Did you purchase sports goods in your favourite store within the last two months? The survey took place from November to December 2018. In total, 238 persons were surveyed, with $43.56 \%$ female, $56.43 \%$ male and $0.01 \%$ transsexual respondents; the mean age was $28.7( \pm 10.0)$ years. We collected sociodemographic and related data including information about gender, age, level of education, income, occupation, origin and level of physical activity (survey and categorisation according to Eurobarometer, 2018); moreover, the type of the favourite retailer (generalist vs. specialist) and the specific information about ISCX matters were collected (Table 1).

3.2.2 Measures. Bustamente and Rubio (2017) conceptualised the ISCX scale as a thirdorder formative scale composed of one second-order reflective dimension (social experience) and three first-order reflective dimensions (cognitive experience, affective experience and physical experience). The second-order reflective dimension (social experience) is conceptualised as a combination of the customer's interaction with other customers and with employees. The formative structure of ISCX implies that the latent construct is formed by its dimensions, and that the dimensions do not share a common theme or that they are not interchangeable (Coltman et al., 2008).

Satisfaction with the retailer was measured by adopting a scale from Dagger et al. (2007) (see Table 2). We used seven-point, agree-disagree Likert scales to examine the construct items. The NPS was measured as a single-item construct with the question "How likely is it that you recommend XY to a friend or colleague?" (Reichheld, 2003), answered on a 0 to 10 rating scale.

3.2.3 Results of the measurement model (Study II). To test for systematic differences between the respondents' favourite sports retailer, we compared how the respondents assessed general sports retailers versus specialised sports retailers in terms of ISCX dimensions. Mean comparisons showed no significant differences in the assessment of these two types of retailers. Thus, we assembled the data for further analyses. We assessed the psychometric properties of the reflective ISCX dimensions (cognitive experience, affective experience, social experience and physical experience) through a confirmatory factor analysis (CFA). The measurement model met the recommended threshold values for the following fit measures (Hu and Bentler, 1999): comparative fit index (CFI $\geq 0.90)$, Tucker-

\begin{tabular}{|c|c|c|c|c|}
\hline \multicolumn{2}{|c|}{ Preferred sports retailer is a. ..(\%) } & \multicolumn{2}{|l|}{ Level of education (\%) } & \\
\hline Generalist & 63.3 & High school & 52.6 & \\
\hline Specialist & 36.7 & $\begin{array}{l}\text { University degree } \\
\text { other }\end{array}$ & $\begin{array}{r}43.8 \\
3.6\end{array}$ & \\
\hline \multicolumn{2}{|l|}{ Nationality (\%) } & Monthly physical activities (\%) & & \\
\hline Austria & 51.0 & $<2$ & 40 & \\
\hline Germany & 39.4 & $2-4$ & 9.8 & \\
\hline Switzerland & 1.3 & $4-6$ & 15.4 & Table 1. \\
\hline \multirow[t]{3}{*}{ other } & 8.3 & $6-10$ & 16.3 & Sociodemographic \\
\hline & & $10-14$ & 14.3 & profile of the \\
\hline & & $>14$ & 3.3 & respondents \\
\hline
\end{tabular}

\section{Customer experience in sports retail stores}


IJSMS

22,2

320
Table 2.

Measurement of the constructs in the conceptual model
Latent constructs and measures

Dimensions of customer in-store experience (ISCX)

"The environment of this retail store, the display of its products, services, etc.:"

Cognitive experience

COG2 Teach me interesting things

COG3 Awaken my curiosity

COG4 Awaken my creativity

COG5 Bring interesting ideas to mind

COG6 Inspire me

COG7 Interest me

Affective experience

AFF1 In a good mood

AFF2 Contented

AFF3 Happy

AFF4 Optimistic

AFF5 Hopeful

AFF6 Enthusiastic

AFF7 Thrilled

Physical experience

PHY1 Energy

PHY2 Vitality

PHY3 Comfort

PHY4 Relaxation

Social experience: interaction with customers ${ }^{\#}$

SK1 I advise customers who ask my opinion on this store's products/ services

SK2 I ask the opinions of customers who shop at this store

SK3 I share opinions with this store's customers

SK4 I interact with this store's customers

SK5 I consider myself a member of the community of customers who shop at this store

Social experience: interaction with employees ${ }^{\#}$

SP1 I give my opinion to this store's employees

SP2 I receive advice from this store's employees

SP3 I ask the opinions of this store's employees

SP4 I share my opinions with this store's employees

SP5 I interact with this store's employees

Satisfaction with the sports retailer

SAT1 My feelings towards XYZ are very positive

SAT2 I feel good about coming to XYZ for the offerings I am looking for

SAT3 Overall I am satisfied with XYZ and the service they provide SAT4 I feel satisfied that XYZ produce the best results that can be achieved for me

CFA-

\begin{tabular}{lllll}
$M$ & $S D$ & FL & CR & AVE \\
\hline
\end{tabular}

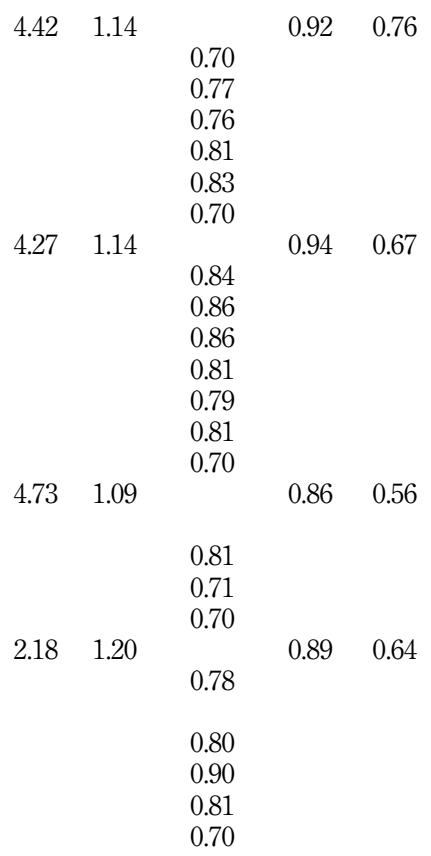

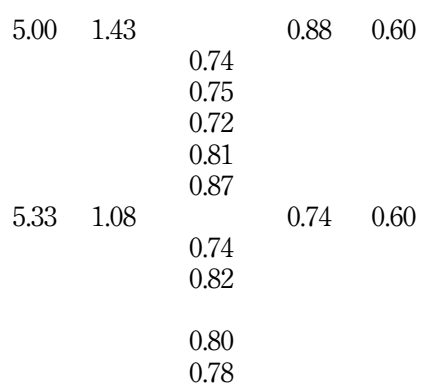

Note(s): All variables were measured on a five-point rating scale $(1=$ strongly disagree, $5=$ strongly agree); $M=$ construct mean, $S D=$ standard deviation, $\mathrm{CFA}-\mathrm{FL}=$ confirmatory factor analysis factor loadings, $\mathrm{CR}=$ composite reliability, AVE $=$ average variance extracted. ${ }^{\#}$ Dimension of the second order construct social experience

Lewis index (TLI $\geq 0.90$ ), root mean square error of approximation (RMSEA $\leq 0.08$ ) and standardised root mean square residual (SRMR $\leq 0.06$ ). All items were tested in the same model and were restricted to load on their respective factors. The factor loadings of the latent constructs were significant $(\phi<0.01)$ and ranged from 0.70 to 0.90 , suggesting acceptable 


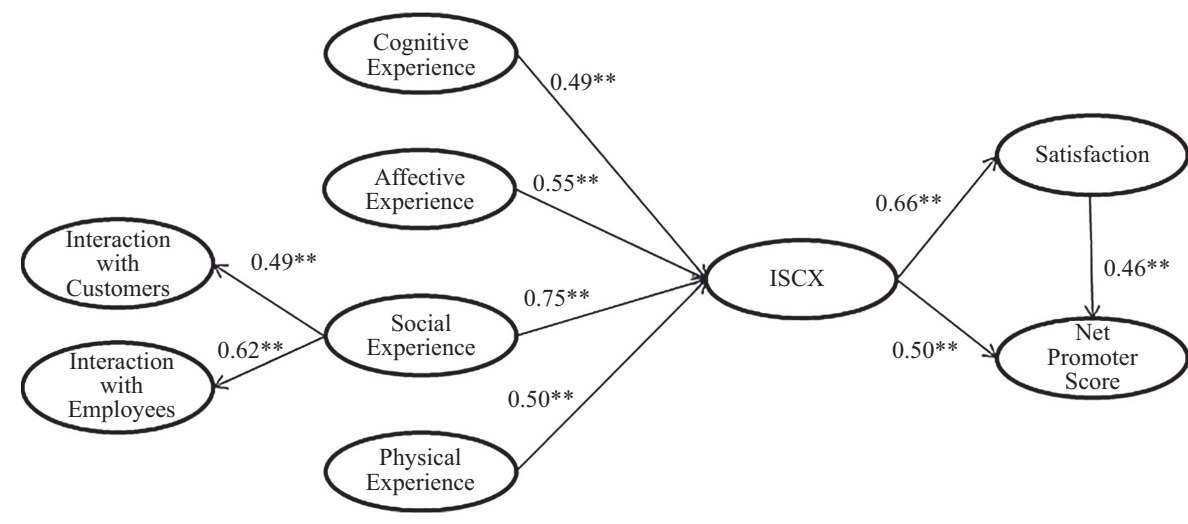

\section{Customer experience in sports retail stores}

\section{1}

construct validity. Next, the internal consistency and validity of the proposed multi-item constructs were evaluated by calculating composite reliability (CR) and the average variance extracted (AVE). CR ranged from 0.74 to 0.94 , indicating good reliability (Hair et al., 1998). The AVE exceeded the recommended minimum value of 0.50 (Bagozzi and Yi, 1988). Table 2 presents the items of the multi-item constructs as well as their factor loadings, AVE and CR.

3.2.4 Results of the structural model. We used covariance-based structural equation modelling (SEM) in Mplus version 5.21 (Muthén and Muthén, 1998-2010) to test the full model. The overall model fit of the SEM yielded satisfying results $\left(\chi^{2}=1400.72, \mathrm{df}=457\right.$, $p=0.00$, CFI/TFI $\geq 0.90$, RMSEA /SRMR $\leq 0.08$ ). SEM facilitates the discovery and confirmation among multiple latent constructs and is particularly suited for higher-order modelling of constructs (Bagozzi and Yi, 2012; Hair et al., 2014).

ISCX was significantly driven by cognitive $(\beta=0.49, p<0.001)$, affective $(\beta=0.55$, $p<0.001)$, physical $(\beta=0.50, p<0.001)$ and social $(\beta=0.75, p<0.001)$ experience dimensions. The social dimension of ISCX is significantly reflected by the dimension's interaction with customers $(\beta=0.49, p<0.001)$ and interaction with employees $(\beta=0.62$, $p<0.001)$. ISCX was positively correlated with satisfaction with the retailer $(\beta=0.66$, $p<0.001)$, thus supporting H1, and the NPS $(\beta=0.50, p<0.001)$, thus supporting $\mathrm{H} 2$. Additionally, satisfaction with the retailer was positively correlated with the NPS ( $\beta=0.46$, $p<0.001)$. Figure 2 shows the standardised path coefficients of the full study model.

\section{Conclusions and discussion \\ 4.1 Summary}

Customer experience in offline retail stores has been studied (Bustamente and Rubio, 2017), but there is still a call for more research in different contexts to develop comprehensive knowledge about CX (Lemon and Verhoerf, 2016). The aims of the current study were to provide deeper insights into the construct of ISCX, including satisfaction and the NPS in a sports retail setting, to implement ISCX in the field of sports marketing and to emphasise and discuss the peculiarities of the sports business and sports customers in sports retailing. The results of the study show that ISCX has a significant influence on customers' satisfaction with the sports retailer and their likeliness to recommend the store to friends measured by the NPS; in turn, this likeliness was significantly associated with customers' satisfaction with the retailer. Notably, social responses to other actors involved in the service encounter, for example, the interaction with employees, play a significant role for the ISCX. Sports customers strive not only for the functional benefits inherent in the interaction with customers and employees but also for the social benefits. 
IJSMS

22,2

\subsection{Research contribution}

The qualitative focus group (Study I) aimed to investigate if there is a difference between ISCX in sports stores and in non-sports stores. The quantitative study (Study II) extended the knowledge by analysing ISCX in a sports retail environment, replicating the ISCX scale, and examining the influence of ISCX on the NPS.

First, we conceived ISCX as a construct composed of stimuli (cognitive, affective and physical) and internal social responses to other actors involved in the service encounter in the specific context of the offline sports retail stores. The ISCX findings confirmed the four experiential components identified by Verhoef et al. (2009) in a retail service context.

The cognitive experience in a store, represented by items like "teach me interesting things" or "interest me", influences the ISCX. Terblanche (2018) identified a positive effect of the product presentation on cognitive stimuli. Cognitive activation occurs when stimuli encourage content creation with meaning for the customer (Bustamente, 2017). Positive mental representation resulting from cognitive activations generated by in-store stimuli is especially important, because it contributes to changing the customer's perception of shopping from that of a merely functional act to an experiential one (Bustamente, 2017). According to the results of the focus groups, customers of sports retail stores tend to have good basic know-how about their favourite sport and the corresponding equipment; hence, appropriate cognitive stimuli could emphasise the retailer's expertise in the customer's mind and lead to a better in-store experience.

Affective items reflect important emotional descriptors with a positive valence. Emotional conditions, such as being "happy", "in a good mood" and "thrilled", influence a customer's decision-making (Davidson et al., 1990, 1999). Lichtlè and Plichon (2014) identified an impact of the store atmosphere on the affective stimuli of customers and furthermore on their satisfaction with the store. Pullman and Gross (2004) as well as Andreu et al. (2006) found out that in-store affective stimuli increase not only the satisfaction with the sports store but also loyalty to the retailer. Positive responses to in-store stimuli are fundamental as they help customers to restrict the number of options, reduce the time required to make decisions and simplify evaluation (Bustamente and Rubio, 2017). Sports customers should feel attracted by in-store stimuli, which are designed to put them in a good mood or awake emotions of happiness; eventually, the emotional spirit that can be felt when practising sport could be transferred to the sports retail store. Even the joyful anticipation of practising the preferred sport with equipment offered in the store could influence the affective stimuli. These findings are supported by the focus group participants who confirmed that sport has a high priority in their lives and is associated with many positive emotional conditions.

The physical component represents the importance of physiological well-being during the shopping experience. Customers experiencing "energy", "vitality" and "comfort" during their store visit reveal a state of physiological well-being affected by the store environment (KuijtEvers et al., 2004). Terblanche (2018) described a positive effect of the offline store experience on the customer satisfaction with the retailer. Sports customers strive for example for vitality and energy by practising sport and thus feel similar stimuli when shopping in a sports retail store; these stimuli influence the ISCX. Additionally, and this aspect is especially relevant for sports tourism areas, sport shopping can be part of sports customers' holiday activities and is supposed to evoke well-being.

Finally, social responses to other actors involved in the service encounter, for example, the interaction with customers ("I advise customers who ask my opinion on this store's product services") or with employees ("I receive advice from this store's employees"), play a significant role for the ISCX. The focus group participants stated that they see themselves as well-informed customers, but additionally they want to have their own opinion confirmed and expanded by a sales expert; consequently, they see service as one of the most important features of a sports retail store. Customers strive for not only the functional benefits inherent 
in the interaction with customers and employees, but also for the social benefits (Hu and Jasper, 2006; Pan and Zinkhan, 2006), which range from a casual conversation with employees or customers to a deep feeling of social involvement with the retail store. O'Donnell et al. (2016) described sports customers as "market mavens", who want to get in contact with other customers or employees. Support by and expertise of store staff are very important (Lichtlè and Plichon, 2014). In our context, this means that sports customers want to interact with employees, discuss with other customers and come to a product decision linked with a memorable in-store experience.

Second, this paper contributes theoretically by finding that the ISCX significantly affects the customer's satisfaction with the sports retailer. Bustamente and Rubio (2017) showed a strong, positive and significant relationship between ISCX and loyalty.

Many studies have concluded that satisfaction has a positive relationship with customer patronage intention (Bhattacherjee, 2001; Cronin et al., 2000; Lin et al., 2005; Udo et al., 2010). If customers have a higher level of satisfaction with their shopping experiences, they will have stronger intentions to purchase (Zeithaml et al., 1996). Our study estimates the finding that there is a strong, positive and significant relationship between ISCX and satisfaction - in other words: sports customers' store satisfaction refers to the subjective evaluation of whether the store meets or exceeds their expectations. A more positive ISCX rating leads to higher satisfaction with the retailer; thus, proper store management including all the theoretical findings about the components affecting ISCX is necessary to satisfy sports customers. In contrast to online stores, offline stores have the chance to create memorable shopping experiences, resulting in high customer satisfaction with the retailer.

Third, the ISCX significantly affects the NPS, the recommendation rate to friends. The link between customer satisfaction and favourable business outcomes is well-established (Anderson et al., 1997) and generates great interest in measuring customer satisfaction and one of its key concepts, the NPS (Reichheld, 2003). Reichheld (2003) linked satisfaction, recommendation and business outcomes by claiming that the NPS is the sole metric required to understand the effectiveness of a business from a customer's perspective. This view has been contested vigorously by researchers trying to replicate his research (Keiningham et al., 2007). However, our study expanded the ISCX scale of Bustamente and Rubio (2017) with the finding that there is a strong link between the ISCX and NPS in sports retail stores. More than $80 \%$ of customers trust in recommendations of friends or family (Nielsen, 2015). Klein, Falk, Esch and Gloukhovtsev (2016) found out that innovative experiences, an interactive environment and an appealing in-store atmosphere play a key role for the recommendation rate. In our context, the ISCX significantly affected the NPS of the sports retailer. As sports retail customers will recommend a store to their friends if the ISCX is positive, these findings indicate that the ISCX is central to creating and maintaining stable recommendation rates. Sports customers need a pleasant in-store experience mirroring their understanding of sport shopping to tell their friends about a particular retailer and recommend the store.

Fourth, this study contributes theoretically by finding that customers' satisfaction with the sports retailer significantly affects the NPS. A favourable ISCX is a strong motivator for maintaining the customer's satisfaction with the store and drives higher recommendation rates in terms of the NPS. In other words, if sports retailers are able to improve the ISCX, sports customers' satisfaction, and subsequently the NPS, will rise.

\subsection{Managerial implications}

The current study has relevance for sports marketers' and management professionals' knowledge and offers improvements for creating CX in sports retail stores. ISCX provides a measure helping managers to benchmark and track their performance over time. More importantly, it illustrates a detailed structure, whereby managers can determine which
Customer
experience in
sports retail
stores

323 
IJSMS

22,2

324 attributes of the ISCX are most strongly associated with the marketing outcomes they are trying to achieve.

Cognitions, feelings and social as well as physical responses shape the ISCX and evoke instore stimuli; thus, retail managements and the physical shopping environment influence the ISCX (Bustamente and Rubio, 2017). The in-store environment needs to fulfil the cognitive information that sports customers demand. Driven by the rapid development of e-commerce and new digital channels (Zhang et al., 2017), retailers should support cognitive store stimuli with online tools such as augmented reality to take advantage by integrating them at the point of sale. Customers could immerse in a movie showing technical features and diverse applications combined with emotional content influencing the affective shopping experience in the retail store. Digital mirrors could make it easier and more pleasant to sell apparel; the affective and physical stimuli could be positively influenced by this innovation.

Additionally, support provided by educated employees in the store could enhance the social interaction with the customer. Schwarz and Hunter (2008) examined that sports retailing is not a "normal" retail business; sports retail employees have to be very welleducated and credible in their expertise. As buying sports equipment demands extensive advice, the social interaction between the customer and either an employee or another customer, such as a market insider, is key.

Satisfaction with the retailer is strongly influenced by the ISCX. Accordingly, Kotler et al. (2016) expanded the AIDA (attention, interest, desire and action) formula by satisfaction (AIDAS). Also social media and other networks, which are huge information platforms, have positive or negative impacts on the ISCX.

Satisfaction influences the recommendation rate measured by the NPS; hence, sports retail stores need to drive marketing campaigns that enable customers to recommend the store to friends. The opportunity to shop in a sports retail store with a dedicated friend and getting a shopping discount could enhance the satisfaction-recommendation link. Additionally, using influencers as part of sports store retailing programmes could merge online and offline retailing; recommendations through the so-called experts could support the connection between ISCX, satisfaction and recommendation.

Based on the attributes and dimensions of the ISCX in sports retail stores, we believe that our findings are of particular relevance to other high involvement, high-contact professional services.

\subsection{Limitations and directions for future research}

As any study, also this research has some limitations. First, our study focused on a particular retail setting and was conducted in one country with a sample of sports customers. While it seems reasonable to suggest that these findings will extend to similar service settings, this assumption needs to be researched. The relationship between a sports retailer and its customers is driven by peculiarities influencing the sports business. Other researchers may wish to investigate more hedonic consumption services and other non-contractual services.

Second, this study provided insights into the dynamics of providing sports goods and the effect on customers' shopping behaviour. It could be very interesting to evaluate services in the sports retail branch, for example ski or bike retail stores.

Third, researchers and practitioners have argued the need for more scholarly research in different contexts to develop comprehensive knowledge of ISCX and especially of its formation, effectiveness and implementation (Lemon and Verhoef, 2016). In addition to a more comprehensive understanding of $\mathrm{CX}$, instruments are needed to improve managerial practices across different service contexts (Lipkin, 2016). Verhoef et al. (2009) called for the development of a scale to measure a broad range of ISCX; this scale should go beyond classical cognitive and affective responses to shopping stimuli. Managerial needs have reinforced these calls. 
Fourth, in today's retail service environment, where customers have more control than ever, where the battle between online and offline plays a main role and where CX is a key element by which firms differentiate themselves from competitors and improve customer engagement, research could help managers to perform better by developing instruments to understand, achieve and evaluate CX.

Fifth, the study examined ISCX in sports retailing in just one country. The replication of our research in other countries would enable the generalisation of the results and the development of an even stronger theory.

Sixth, a follow-up study collecting data about one particular retailer within a limited period of time would improve internal validity of the results. Moreover, a follow-up study could include growth rates to examine the influence of NPS on growth.

\section{References}

Anderson, E., Fornell, C. and Rust, R. (1997), "Customer satisfaction, productivity, and profitability: differences between goods and services", Marketing Science, Vol. 16 No. 2, pp. 129-145.

Andreu, L., Bigné, E., Chumpitaz, R. and Swaen, V. (2006), "How does the perceived retail environment influence consumers' emotional experience? Evidence from two retail settings", International Review of Retail Distribution and Consumer Research, Vol. 16 No. 5, pp. 559-578.

Bagdare, S. and Jain, R. (2013), "Measuring retail customer experience", International Journal of Retail and Distribution Management, Vol. 41 No. 10, pp. 790-804.

Bagozzi, R.P. and Yi, Y. (1988), "On the evaluation of structural equation models", Journal of the Academy of Marketing Science, Vol. 16 No. 1, pp. 74-94.

Bagozzi, R.P. and Yi, Y. (2012), "Specification, evaluation, and interpretation of structural equation models", Journal of the Academy of Marketing Science, Vol. 40 No. 1, pp. 8-34.

Beck, J. (2013), "Multichannel marketing is a perfect storm of synergies [Web log post]", available at: http://blogs.gartner.com/jennifer-beck/multichannel-marketing-is-a-perfect-storm-ofsynergies-2 (accessed 3 July 2013).

Bhattacherjee, A. (2001), "An empirical analysis of the antecedents of electronic commerce service continuance”, Decision Support Systems, Vol. 32 No. 2, pp. 201-214.

Bielefeldt Bruun, M. and Langkjær, M.A. (2016), "Sportswear: between fashion, innovation and sustainability", Fashion Practice, Vol. 8 No. 2, pp. 181-188.

Block, J. and Kuckertz, A. (2018), "Seven principles of effective replication studies: strengthening the evidence base of management research", Management Review Quarterly, Vol. 68, pp. 355-359.

Brakus, J., Schmitt, B. and Zarantonello, L. (2009), "Brand experience: what is it? How is measured? Does it affect loyalty?", Journal of Marketing, Vol. 73 No. 2, pp. 52-68.

Brodie, R. (2006), "The service brand and the service-dominant logic: missing fundamental premise or the need for stronger theory?", Marketing Theory, Vol. 6 No. 3, pp. 363-379.

Bustamente, J.C. and Rubio, N. (2017), "Measuring customer experience in physical retail environments", Journal of Service Management, Vol. 28 No. 5, pp. 884-913.

Calabuig, F., Prado-Gascó, V., Crespo, J., Núñez-Pomar, J. and Añó, V. (2015), "Spectator emotions: effects on quality, satisfaction, value, and future intentions", Journal of Business Research, Vol. 68 No. 7 , pp. $1445-1449$.

Chiu, W. and Leng, H.K. (2015), "Consumers intention to purchase counterfeit sporting goods in Singapore and Taiwan", Asia Pacific Journal of Marketing and Logistics, Vol. 28 No. 1, pp. 23-36.

Clemes, M., Brush, G. and Collins, M. (2011), "Analysing the professional sport experience: a hierarchical approach", Sport Management Review, Vol. 14 No. 4, pp. 370-388.

Coltman, T., Devinney, T., Midlgey, D.F. and Venaik, S. (2008), "Formative versus reflective measurement models: two applications of formative measurement", Journal of Business Research, Vol. 61 No. 12, pp. 1250-1262.

\section{Customer experience in sports retail stores}


IJSMS

22,2

Cronin, J.J., Brady, M.K. and Hult, G.T.M. (2000), “Assessing the effects of quality, value, and customer satisfaction on consumer behavioral intentions in service environments", Journal of Retailing, Vol. 76 No. 2, pp. 193-218.

Dagger, T., Sweeney, J. and Johnson, L. (2007), "A hierarchical model of health service quality: scale development and investigation of an integrated model", Journal of Service Research, Vol. 10 No. 2, pp. 123-142.

David, M. and Sutton, C.D. (2004), Social Research: The Basics, Sage Publications, Thousand Oaks, CA.

Davidson, R.J., Chapman, J.P., Chapman, L.J. and Henriques, J.B. (1990), "Asymmetrical brain electrical activity discriminates between psychometrically-marched verbal and spatial cognitive tasks", Psychophysiology, Vol. 27 No. 5, pp. 528-543.

Davidson, R.J., Coe, C.C., Dolski, I. and Donzella, B. (1999), "Individual differences in prefrontal activation asymmetry predict natural killer cell activity at rest and in response to challenge", Brain, Behavior, and Immunity, Vol. 13 No. 2, pp. 93-108.

De Keyser, A., Lemon, K.N., Klaus, P. and Keiningham, T.L. (2015), "A framework for understanding and managing the customer experience”, Working Paper No. 15-121, Marketing Science Institute, Cambridge, MA.

Eurostat (2019), "E-commerce statistics for individuals", available at: https:/ec.europa.eu/eurostat/de/ data/database.

Funk, D.C. and James, J.D. (2006), "Consumer loyalty: the meaning of attachment in the development of sport team allegiance", Journal of Sport Management, Vol. 20 No. 2, pp. 189-217.

Funk, D. (2017), "Introducing a Sport Experience Design (SX) framework for sport consumer behaviour research", Sport Management Review, Vol. 20 No. 20, pp. 145-158.

Gammelsæter, H. (2020), "Sport is not industry: bringing sport back to sport management”, European Sport Management Quarterly, doi: 10.1080/16184742.2020.1741013.

García-Fernández, J., Gálvez-Ruíz, P., Fernández-Gavira, J., Vélez-Colón, L., Pitts, B. and Bernal-García, A. (2018), "The effects of service convenience and perceived quality on perceived value, satisfaction and loyalty in low-cost fitness centers", Sport Management Review, Vol. 21, pp. 250-262.

Greenwell, T.C., Fink, J.S. and Pastore, D.L. (2002), "Assessing the influence of the physical sports facility on customer satisfaction within the context of the service experience", Sport Management Review, Vol. 5 No. 2, pp. 129-148.

Grewal, D., Levy, M. and Kumar, V. (2009), "Customer experience management in retailing: an organizing framework", Journal of Retailing, Vol. 85 No. 1, pp. 1-14.

Hair, J., Anderson, R., Tatham, R. and Black, W. (1998), Multivariate Data Analysis, 5th ed., Prentice Hall, New Jersey, NJ.

Hair, J.F., Gabriel, M. and Patel, V. (2014), "AMOS covariance-based structural equation modeling (CBSEM): guidelines on its application as a marketing research tool", Brazilian Journal of Marketing, Vol. 13 No. 2, pp. 44-53.

Heinonen, K., Strandvik, T. and Voima, P. (2013), "Customer dominant value formation in service", European Business Review, Vol. 25 No. 2, pp. 104-123.

Helkkula, A., Kelleher, C. and Pihlström, M. (2012), “Characterizing value as an experience”, Journal of Service Research, Vol. 15 No. 1, pp. 59-75.

Herhausen, D., Binder, J., Schoegel, M. and Hermann, A. (2015), "Integrating bricks with clicks: retailerlevel and channel-level outcomes of online-offline channel integration”, Journal of Retailing, Vol. 91 No. 2, pp. 309-325.

Hertwig, R., Barron, G., Weber, E.U. and Erev, I. (2004), "Decisions from experience and the effect of rare events in risky choice", Psychological Science, Vol. 15 No. 8, pp. 534-539.

Hess, R., Nicholson, M., Stewart, B. and De Moore, G. (2008), A National Game: A History of Australian Rules Football, Viking Penguin, Camberwell. 
Hirschman, E. and Holbrook, M. (1982), "Hedonic consumption: emerging concepts, methods and propositions", Journal of Marketing, Vol. 46 No. 3, pp. 92-101.

Horbel, C., Popp, B., Woratschek, H. and Wilson, B. (2016), "How context shapes value co-creation: spectator experience of sport events", Service Industries Journal, Vol. 36 Nos 11-12, pp. 510-531.

Hu, L. and Bentler, P.M. (1999), "Cutoff criteria for fit indexes in covariance structure analysis: conventional criteria versus new alternatives", Structural Equation Modeling: A Multidisciplinary Journal, Vol. 6 No. 1, pp. 1-55.

$\mathrm{Hu}, \mathrm{H}$. and Jasper, C.R. (2006), "Social cues in the store environment and their impact on store image", International Journal of Retail and Distribution Management, Vol. 34 No. 1, pp. 25-48.

Hwang, J. and Lee, K.-W. (2018), "The antecedents and consequences of golf tournament spectators' memorable brand experiences", Journal of Destination Marketing and Management, Vol. 9, pp. 1-11.

Keiningham, T., Cooli, B., Andreasseen, T. and Aksoy, L. (2007), "A longitudinal examination of Net Promoter and firm revenue growth", Journal of Marketing, Vol. 71, pp. 39-51.

Klaus, P. and Maklan, S. (2013), "Towards a better measure of customer experience", International Journal of Market Research, Vol. 55 No. 2, pp. 227-246.

Klein, J.F., Falk, T., Esch, F.-R. and Gloukhovtsev, A. (2016), "Linking pop-up brand stores to brand experience and word of mouth: the case of luxury retail", Journal of Business Research, Vol. 69 No. 12 , pp. $5761-5767$.

Kloosterman, P. and Giebel, K. (2007), "T-kit on educational evaluation in youth work: Tasting the soup", Council of Europe, Strasbourg Cedex.

Knobloch-Westerwick, S., David, P., Eastin, M.S., Tamborini, R. and Greenwood, D. (2009), "Sports spectators' suspense: affect and uncertainty in sports entertainment", Journal of Communication, Vol. 59, pp. 750-767.

Kotler, P., Armstrong, G., Harris, L.C. and Piercy, N. (2016), Grundlagen des Marketing [Basics of Marketing], Pearson Education, Hallbergmoos.

Kuijt-Evers, L.F., Groenesteijn, L., De Looze, M. and Vink, P. (2004), "Identifying factors of comfort in using hand tools", Applied Ergonomics, Vol. 35 No. 5, pp. 453-458.

Kuppelwieser, V.G. and Klaus, P. (2020), "Measuring customer experience quality: the EXQ scale revisited", Journal of Business Research.

Kwak, D.H., Kim, Y.K. and Hirt, E.R. (2011), "Exploring the role of emotions on sport consumers' behavioral and cognitive responses to marketing stimuli”, European Sport Management Quarterly, Vol. 11 No. 3, pp. 225-250.

Lemon, K. and Verhoef, P. (2016), "Understanding customer experience throughout the customer journey", Journal of Marketing, Vol. 80 No. 11, pp. 69-96.

Lichtlé, M.-C. and Plichon, V. (2014), "Emotions experienced in retail outlets: a proposed measurement scale", Recherche et Applications en Marketing, Vol. 29 No. 1, pp. 3-24.

Lin, C.S., Wu, S. and Tsai, R.J. (2005), "Integrating perceived playfulness into expectation confirmation model for web portal context”, Information and Management, Vol. 42 No. 5, pp. 683-693.

Lipkin, M. (2016), “Customer experience formation in today's service landscape”, Journal of Service Management, Vol. 27 No. 5, pp. 678-703.

Litosseliti, L. (2003), Using Focus Groups in Research, Bloomsbury Publishing, London.

Liu, D. (2016), "Social impact of major sports events perceived by host communities", International Journal of Sports Marketing and Sponsorship, Vol. 17 No. 1, pp. 78-91.

Lohman, C., Fortuin, L. and Wouters, M. (2004), "Designing a performance measurement system: a case study”, European Journal of Operational Research, Vol. 156, pp. 267-286. 
IJSMS

22,2

Madrigal, R. and Chen, J. (2008), "Moderating and mediating effects of team identification in regard to causal attributions and summary judgments following a game outcome", Journal of Sport Management, Vol. 22, pp. 717-733.

Marketing Science Institute (2016), "Research priorities of the marketing science institute, 2016-2018", available at: https://www.msi.org/uploads/articles/MSI_RP16-18.pdf.

Meyer, C. and Schwager, A. (2007), "Understanding customer experience", Harvard Business Review, Vol. 85 No. 2, pp. 116-126.

Mullin, B.J., Hardy, S. and Sutton, W.A. (2007), Sport Marketing, 3rd ed., Human Kinetics, Champaign, IL.

Muthén, L.K. and Muthén, B.O. (1998-2010), Mplus User's Guide, 6th ed., Muthén \& Muthén, Los Angeles, CA.

Nielsen (2015), "Vertrauen in Werbung weltweit: Gewinner-Strategien für eine Medienlandschaft im Wandel - September 2015 [Trust in advertising worldwide: winner strategies for a changing media landscape - September 2015]", available at: https://www.nielsen.com/content/dam/ nielsenglobal/de/docs/Nielsen_Global_Trust_in_Advertising_Report_DIGITAL_FINAL_DE.pdf.

Nuviala, A., Grao-Cruces, A., Turpin, J.A. and Nuviala, R. (2012), "Perceived service quality, perceived value and satisfaction in groups of users of sports organizations in Spain", Kinesiology, Vol. 44 No. 1, pp. 94-103.

O'Donnell, K.A., Strebel, J. and Mortimer, G. (2016), "The thrill of victory: women and sport shopping”, Journal of Retailing and Consumer Services, Vol. 28, pp. 240-251.

Pan, Y. and Zinkhan, G. (2006), "Determinants of retail patronage: a meta-analytical perspective", Journal of Retailing, Vol. 82 No. 3, pp. 229-243.

Peck, J. and Childers, T.L. (2003), "Individual differences in haptic information processing: the "need for touch" scale", Journal of Consumer Research, Vol. 30 No. 3, pp. 430-442.

Pullman, M. and Gross, M. (2004), "Ability of experience design elements to elicit emotions and loyalty behaviors”, Desicion Science, Vol. 35 No. 3, pp. 551-578.

Reichheld, F.F. (2003), “The one number you need to grow”, Harvard Business Review, Vol. 12, pp. 46-54.

Schwarz, E.C. and Hunter, J.D. (2008), Advanced Theory and Practice in Sport Marketing, ButterworthHeinemann, Oxford.

Shilbury, D., Westerbeek, H., Quick, S., Funk, D. and Karg, D.C.A. (2014), Strategic Sport Marketing, 4th ed., Allen \& Unwin Academic, Crow Nest, NSW.

Smith, A.C.T. and Stewart, B. (2010), "The special features of sport: a critical revisit", Sport Management Review, Vol. 13 No. 10, pp. 1-13.

Smith, A.C.T. and Stewart, B. (2015), Introduction to Sport Marketing, 2nd ed., Routledge, London.

Stewart, R. and Smith, A. (1999), "The special features of sport", Annals of Leisure Research, Vol. 2, pp. 87-99.

Szymanski, S. (2009), Playbooks and Checkbooks: An Introduction to the Economics of Modern Sports, Princeton University Press, Princeton, NJ.

Tajfel, H. (1982), "Social psychology of intergroup relations", Annual Review of Psychology, Vol. 33 No. 1, pp. 1-39.

Terblanche, N.S. (2018), "Revisiting the supermarket in-store customer shopping experience", Journal of Retailing and Consumer Services, Vol. 40, pp. 48-59.

Udo, G.J., Bagchi, K.K. and Kirs, P.J. (2010), “An assessment of customers' e-service quality perception, satisfaction and intention", Internationl Journal of Information Management, Vol. 30 No. 6, pp. 481-492.

Verhoef, P., Lemon, K.N., Parasuraman, A., Roggeveen, A., Tsiros, M. and Schlesinger, L.A. (2009), "Customer experience creation: determinants, dynamics and management strategies", Journal of Retailing, Vol. 85 No. 1, pp. 31-41. 
Wakefield, K.L. and Blodgett, J.G. (1996), "The effect of the servicescape on customers' behavioral intentions in leisure service settings", Journal of Services Marketing, Vol. 10 No. 6, pp. 45-62.

Wang, K. and Goldfarb, A. (2017), "Can offline stores drive online sales?", Journal of Marketing Research, Vol. 54, pp. 706-719.

Yoshida, M. and James, J.D. (2010), "Customer satisfaction with game and service experiences:

Customer experience in sports retail stores antecedents and consequences", Journal of Sport Management, Vol. 24 No. 3, pp. 338-361.

Yoshida, M., James, J.D. and Cronin, J. (2013), "Sport event innovativeness: conceptualization, measurement, and its impact on consumer behaviour", Sport Management Review, Vol. 16 No. 1, pp. 68-84.

Zeithaml, V., Berry, L. and Parasuraman, A. (1996), "The behavioral consequences of service quality", Journal of Marketing, Vol. 60 No. 2, pp. 31-46.

Zhang, P., He, Y. and Shi, C.V. (2017), "Retailer's channel structure choice: online channel, offline channel, or dual channels?", International Journal of Production Economics, Vol. 191, pp. 37-50.

Zuckerman, M. (2007), Sensation Seeking and Risky Behaviour, American Psychological Association, Washington, DC.

\section{Further reading}

Edvardsson, B., Enquist, B. and Johnston, R. (2005), "Cocreating customer value through hyperreality in the prepurchase service experience", Journal of Service Research, Vol. 8 No. 2, pp. 149-161.

Esmark, C.L., Noble, S.M., Bell, J.E. and Griffith, D.A. (2015), "The effects of behavioural, cognitive and decisional control in co-production service experiences", Marketing Letters, Vol. 1 No. 14, pp. 1-14.

European Commission (2018), "Special Eurobarometer 472", available at: https://ec.europa.eu/ commfrontoffice/publicopinion/archives/ebs/ebs_334_de.pdf.

Richins, M.L. (1997), "Measuring emotions in the consumption experience", Journal of Consumer Research, Vol. 24 No. 2, pp. 127-146.

Teixeira, J., Patrício, L., Nunes, N.J., Nóbrega, L., Fisk, R.P. and Constantine, L. (2012), “Customer experience modelling: from customer experience to service design", Journal of Service Management, Vol. 23 No. 3, pp. 362-376.

Verleye, K. (2015), "The co-creation experience from the customer perspective: its measurement and determinants", Journal of Service Management, Vol. 26 No. 2, pp. 321-342.

\section{Corresponding author}

Elisabeth Happ can be contacted at: elisabeth.happ@uibk.ac.at

For instructions on how to order reprints of this article, please visit our website:

www.emeraldgrouppublishing.com/licensing/reprints.htm

Or contact us for further details: permissions@emeraldinsight.com 